\title{
Clinical experience with the Rhône-Poulenc ascites reinfusion apparatus
}

\author{
P. J. A. MoulT* \\ M.B., M.R.C.P. \\ S. P. PARBHOO $\dagger$ \\ Ph. D., F.R.C.S. \\ S. SHERLOCK* \\ M.D., F.R.C.P. \\ *Department of Medicine, $\dagger$ Academic Department of Surgery, Royal Free Hospital, \\ Pond Street, Hampstead, London NW3 2QG
}

\begin{abstract}
Summary
Ascitic ultrafiltration and reinfusion of protein concentrate is of value in selected patients and is, in general, well tolerated. Patients with massive ascites and an unsatisfactory response to diuretic therapy are most suitable, but those with ascitic infection, pulmonary oedema, and terminal liver disease are excluded. Although two of our patients had malignant ascites, reinfusion is not recommended for such patients.

Persistent pulmonary oedema was a contributory cause of death in two patients, and was attributed to reinfusion. Intraperitoneal haemorrhage may occur from a perforated collateral vein and close observation of patients must be continued after the peritoneal catheter has been removed.

A clogged ultrafilter was cleared with urokinase, and further studies of this are indicated.

After ultrafiltration about half the patients were satisfactorily controlled with diuretic drugs, although there is no evidence that reinfusion produces a sustained improvement in diuretic responsiveness.

\section{Patients}

Thirty patients have been treated with the ascites reinfusion apparatus. This total includes the seventeen patients reported by Parbhoo, Ajdukiewicz and Sherlock (1974). Six patients were treated twice, and one three times, making a total of thirty-seven treatment sessions. Twenty-seven patients had cirrhosis, two had malignant ascites, and one the Budd-Chiari syndrome (Table 1). One patient was positive for the hepatitis $B$ antigen.
\end{abstract}

TABLE 1. Diagnosis or type of cirrhosis

\begin{tabular}{lr}
\hline Alcoholic & 10 \\
Cryptogenic & 10 \\
Active chronic hepatitis & 4 \\
Post-hepatitic & 2 \\
Carcinoma of liver & 2 \\
HB-Ag positive & 1 \\
Budd-Chiari & 1 \\
\hline
\end{tabular}

\section{Indications}

All patients were treated at first with bed rest, $\vec{i}$ dietary sodium restriction to $22 \mathrm{mEq} /$ day, and then ${ }_{\infty}^{\circ}$ diuretic drugs. The principal indications for reinfu- $r y$ sion were a poor response to these measures, or $\triangle$ complications of diuretic therapy such as uraemia,, portal-systemic encephalopathy, or cramps. Fourpatients with gastrointestinal haemorrhage from? varices were treated in preparation for emergencye surgery. Other indications were tense ascites re- -9 quiring immediate relief, and economic or socgle $\vec{\omega}$ reasons to shorten the patients' stay in hospi用. ज Reinfusion of ascites has been advocated for t treatment of the functional renal failure of livero disease (Conn, 1973), and eight of our thirty patients had blood urea concentration over $45 \mathrm{mg} / 100 \mathrm{ml}$. In the majority of patients there was more than one indication for treatment.

\section{Results}

The duration of reinfusion ranged from 3 to $24 \mathrm{hr}$ per session (mean $11.6 \mathrm{hr}$ ), and the volume of ultrafiltrate obtained was from 0.4 to 10.01 (mean 4.81 ). Body weight was measured at the start of treatment: and $24 \mathrm{hr}$ later. Weight loss ranged from $2 \cdot 0$ to $16 \cdot 0$. $\mathrm{kg}$ (mean $6.6 \mathrm{~kg}$ ). The difference between weight loss and ultrafiltrate volume is due to the diuresis which 3 frequently accompanies ultrafiltration.

\section{Complications (Table 2)}

Pyrexia up to $40^{\circ} \mathrm{C}$ occurred in twenty-five patients $(68 \%)$. In three of these this was associated with marked aggravation of portal-systemic encephalo- 0 pathy and coliform bacteria were grown from bloodew and ascites. All three recovered with antibiotico treatment. In the remaining patients pyrexia subso sided spontaneously and cultures were negative.

Seven patients $(19 \%)$ leaked ascites from the site? of the peritoneal catheter. Five of the seven leaked externally and two into the scrotum.

Two patients developed pulmonary oedema. These? 
TABle 2. Complications of reinfusion (thirty-seven treatment sessions)

\begin{tabular}{lr}
\hline Pyrexia & $25(68 \%)$ \\
Ascitic leaks & $7(19 \%)$ \\
Infected ascites & $3(8 \%)$ \\
Pulmonary oedema & $2(5 \%)$ \\
Intraperitoneal haemorrhage & $1(3 \%)$ \\
\hline
\end{tabular}

were male, one aged 34 and one 54 , with cryptogenic cirrhosis. Both were admitted with variceal haemorrhage, tense ascites and portal-systemic encephalopathy. Ascites reinfusion was performed in order to reduce the intra-abdominal (and therefore portal) pressure, to minimize protein loss at laparotomy, and to improve respiratory function. After about $12 \mathrm{hr}$ of ultrafiltration both patients developed severe pulmonary oedema which persisted despite blood volume depletion with diuretics and paracentesis. Both required positive pressure ventilation with a positive end-expiratory pressure to maintain arterial oxygen saturation, and this had to be continued until death, 7 and 16 days later respectively. Although fluid overload may have contributed to their pulmonary oedema initially, it is likely that other factors were involved. Hypotension, endotoxaemia, and myocardial failure were considered. Blood cultures were negative. At postmortem the older man had evidence of left ventricular hypertrophy, foci of myocardiolysis and recent subendocardial haemorrhage and fibrosis. Nevertheless pulmonary oedema is an uncommon complication of variceal haemorrhage, and the temporal relationship between reinfusion and the onset of pulmonary oedema makes it likely that reinfusion was a major contributory factor, although the mechanism is unknown.

Another patient being prepared for surgery was found at laparotomy to have bled from a collateral vein on the inner aspect of the anterior abdominal wall. The vein had been perforated by the peritoneal catheter, which was inserted at the usual site, in the midline, $5 \mathrm{~cm}$ below the umbilicus.

\section{Clogging of the ultrafilter}

In the majority of patients the procedure is well tolerated, and in these circumstances it is economical to extract as much oedema fluid as possible. Complete removal of excess extracellular fluid is not achieved since some ascites reforms from the expanded plasma volume when reinfusion ceases. In only about $30 \%$ of our series was there no detectable ascites at the end of reinfusion. In $20 \%$ reinfusion ceased because the tip of the catheter lay high in the abdomen, in a potential space and above the main fluid level. This emphasizes the importance of placing the catheter well down into the pelvis. In the remaining patients (about $50 \%$ ) reinfusion was halted because the ultrafiltration membrane had become clogged with fibrinous material. This occurs either because of a low flow rate through the apparatus, or because of clots which form within the abdomen, and are seen to pass along the input tubing and into the ultrafilter. The addition of a filter at the input of the ultrafilter has unfortunately not prevented this complication since minor agitation allows the clots to pass through. There was no relationship between the incidence of clogging and the ascitic protein concentration.

An attempt to prevent clogging in one patient was made by infusing urokinase, a plasminogen activator, into the ascitic fluid immediately after leaving the abdomen. This was given at the rate of 1000 Ploug $\mathrm{u} / \mathrm{hr}$, but failed to prevent obstruction by fibrinous clots. The membranes were then isolated (Fig. 1) and flushed with 5000 Ploug $u$ of urokinase in $50 \mathrm{ml} 0.9 \% \mathrm{NaCl}$, followed by $50 \mathrm{ml} 0.9 \% \mathrm{NaCl}$

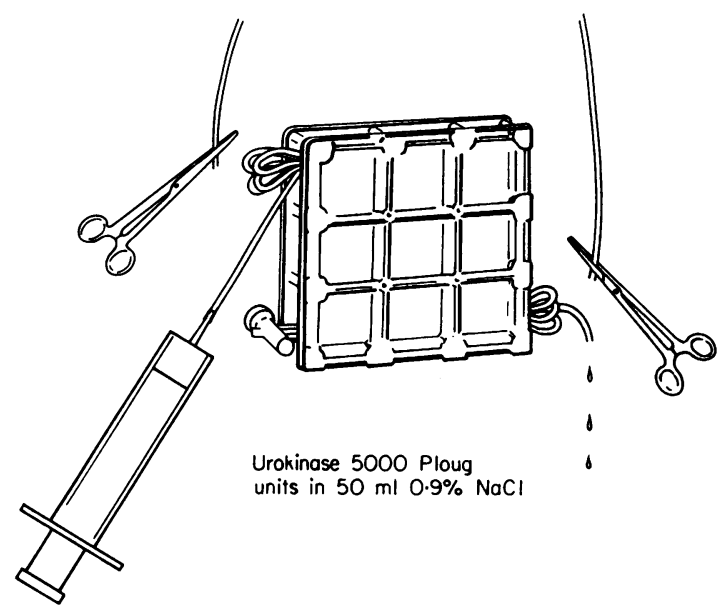

Fig. 1

alone. This procedure was successful in unblocking the ultrafilter and restoring normal function in one patient, but failed on another occasion. 5000 Ploug $u$ of urokinase cost $£ 10.75$ which compares with $£ 29$ for a fresh ultrafilter.

\section{Follow-up}

Six patients died within 3 weeks of treatment, one from severe alcoholic hepatitis, and five from gastrointestinal haemorrhage. Reinfusion may have contributed to the deaths of the two who developed pulmonary oedema.

Of the remainder, thirteen were followed up after discharge from hospital, for periods up to 2 years (mean 10 months). Nine of these thirteen patients have died. All thirteen required diuretic drugs for recurrence of ascites although one patient remained ascites-free without diuretics for the first 4 months. 
In about $50 \%$ of the patients followed up, ascites was satisfactorily controlled with diuretic drugs.

\section{Acknowledgments}

We thank the house physicians and nursing staff who assisted with the reinfusions, and May and Baker Limited for providing the apparatus.

\section{References}

ConN, H.O. (1973) A rational approach to the hepatorena $\subseteq$ syndrome. Gastroenterology, 65, 321.

ParbHoO, S.P., AJdukiewicz, A. \& SHerlock, S. (1974) Treatment of ascites by continuous ultrafiltration and $\bar{C}$ reinfusion of protein concentrate. Lancet, i, 949. 